\title{
Three-Dimensional Structure of the Complex between the Mitochondrial Matrix Adenylate Kinase and Its Substrate AMP¥
}

\author{
Kay Diederichs and Georg E. Schulz* \\ Institut für Organische Chemie und Biochemie der Universität, Albertstrasse 21, 7800 Freiburg i.Br., West Germany \\ Received October 27, 1989; Revised Manuscript Received April 16, 1990
}

\begin{abstract}
Crystals of adenylate kinase from beef heart mitochondrial matrix (EC 2.7.4.10) complexed with its substrate AMP were analyzed by X-ray diffraction. The crystal structure was solved by multiple isomorphous replacement and solvent flattening at a resolution of $3.0 \AA$. There are two enzyme-substrate molecules in the asymmetric unit. The resolution was extended to $1.9 \AA$ by model building and refinement using simulated annealing. The current $R$-factor is $28.4 \%$. The model is given as a backbone tracing for residues 5-218. The enzyme can be subdivided into three domains, the relative arrangements of which differ slightly but significantly between the two crystallographically independent molecules. When compared with other adenylate kinase structures, the chain fold is similar but the observed domain arrangement differs grossly, suggesting that large parts of the enzyme move during catalysis. The observed binding site of AMP is described. Its location in conjunction with data from homologous proteins clarifies the nucleotide-binding sites of the adenylate kinases. Previous assignments of these sites derived from X-ray crystallographic and nuclear magnetic resonance analyses are discussed.
\end{abstract}

\begin{abstract}
A denylate kinase from beef heart mitochondrial matrix (AK3,1 GTP:AMP phosphotransferase, EC 2.7.4.10) is a monomeric enzyme that catalyzes the reaction $\mathrm{Mg}^{2+} \mathrm{GTP}+$ $\mathrm{AMP} \rightleftharpoons \mathrm{Mg}^{2+} \mathrm{GDP}+\mathrm{ADP}$. The enzyme is essential for the biosynthesis of ADP from AMP. The polypeptide chain consists of 225 amino acid residues with $M_{\mathrm{r}}=25469$ and belongs to the group of large variants within the adenylate kinase family (Wieland et al., 1984; Tomasselli et al., 1986). The overall sequence homology to other adenylate kinases is rather low: $37 \%$ identical amino acid residues with the large variant AKyst and $24 \%$ with the small variant AK1 pig. Clear homology occurs in regions $A, B, C, D, e l, e 2, F$, and $G$ as designated by Schulz et al. (1986). Region $A$ contains the typical giant anion hole (Dreusicke \& Schulz, 1986), which is also found in several other nucleotide-binding proteins (Walker et al., 1982; Karn et al., 1983; Hurley et al., 1984; deVos et al., 1988). In contrast to other adenylate kinase structures that have been solved either without substrate (Dreusicke et al., 1988; Reuner et al., 1988) or with the symmetric double-substrate-mimicking inhibitor $\mathrm{Ap}_{5} \mathrm{~A}$ (Egner et al., 1987; Mueller \& Schulz, 1988), crystalline AK3 is associated with one of its substrates, namely AMP. Thus, the structure should indicate which of the two adenine sites of $\mathrm{Ap}_{5}$ A corresponds to AMP and which to ATP. Jencks (1975) has pointed out that kinases should undergo an induced fit during catalysis to prevent water from accepting the transferred phosphoryl group. It is therefore of interest to determine the structures of adenylate kinases without substrate and with one and two substrates bound and to compare them. The conformational differences should then allow conclusions on the molecular movements during catalysis.
\end{abstract}

\section{Materials AND Methods}

Crystals and Data Collection. The enzyme was a kind gift of Drs. Tomasselli and Noda (Tomasselli et al., 1979; To-

\footnotetext{
¥ The coordinates of both AK3-AMP complexes are deposited as file 1AK3 at the Protein Data Bank, Brookhaven, NY.

* To whom correspondence should be addressed.
}

masselli \& Noda, 1979), who initially grew crystals without substrate (Pai et al., 1983) and later grew cocrystals with the substrate AMP. An identical crystal form could be grown from the enzyme isolated from bovine liver (Leistler, 1987), but these were not further analyzed. Crystals were grown at $20^{\circ} \mathrm{C}$ by the hanging drop method. The drops $(15-20 \mu \mathrm{L})$ contained $12 \mathrm{mg} / \mathrm{mL}$ enzyme, $75 \mathrm{mM}$ MOPS at pH $6.5,1$ $\mathrm{mM}$ EDTA, $0.1 \% \mathrm{NaN}_{3}, 3 \mathrm{mM}$ AMP, and $12 \%$ (w/v) PEG8000. As reservoir we used $500 \mu \mathrm{L}$ of $16 \%(\mathrm{w} / \mathrm{v})$ PEG-8000 in $75 \mathrm{mM}$ MOPS at $\mathrm{pH} 6.5$. Crystals grew within 1-2 weeks to a maximum size of $3000 \times 480 \times 240 \mu \mathrm{m}^{3}$; the usual sizes were $900 \times 300 \times 150 \mu \mathrm{m}^{3}$. For crystal storing, handling, and soaking with heavy-atom compounds, we used a buffer containing $75 \mathrm{mM}$ MOPS at pH 6.5, $1 \mathrm{mM}$ EDTA, $0.1 \%$ $\mathrm{NaN}_{3}, 3 \mathrm{mM} \mathrm{AMP}$, and 16\% (w/v) PEG-8000.

Initial X-ray photographs showed that the crystals diffract to a resolution of at least $2.0 \AA$. The space group was determined as $P 2_{1} 2_{1} 2_{1}$ with cell dimensions $a=49.9( \pm 0.1) \AA$, $b=67.0( \pm 0.2) \AA$, and $c=155.4( \pm 0.3) \AA$. Assuming two molecules in the asymmetric unit, we find $V_{M}=2.55 \AA^{3} / \mathrm{Da}$, which is in the normal range (Matthews, 1968), and a solvent content of $52 \%$ with a protein density of $1.35 \mathrm{~g} / \mathrm{mL}$. Data were collected on a four-circle diffractometer (modified model $P 2{ }_{1}$, Nicolet) at $6-8{ }^{\circ} \mathrm{C}$, using $\mathrm{Ni}$-filtered $\mathrm{Cu} \mathrm{K} \alpha$ radiation as described earlier (Thieme et al., 1981). The typical $\omega$ scan ranges and measuring times of the reflections were $0.5^{\circ}$ and $0.8 \mathrm{~min}$, respectively.

Native data were collected in seven shells in the resolution range $\infty-2.5 \AA$. The shells were scaled by using a separate native data set containing the 30 strongest reflections of each

\footnotetext{
' Abbreviations: AKeco, adenylate kinase from Escherichia coli (EC 2.7.4.3); AK1 pig, adenylate kinase from pig muscle cytosol; AKyst, adenylate kinase from bakers' yeast; $\mathrm{AK} 3$, adenylate kinase from beef heart mitochondrial matrix (EC 2.7.4.10); $\mathrm{Ap}_{5} \mathrm{~A}, P^{1}, P^{5}$-bis $\left(5^{\prime}-\right.$ adenosyl)pentaphosphate; $B$-factor, crystallographic temperature factor; EDTA, ethylenediaminetetraacetate; mir, multiple isomorphous replacement; MOPS, 3-( $N$-morpholino)propanesulfonic acid; NCS, noncrystallographic symmetry; PEG, poly(ethylene glycol); rms, root mean square.
} 


\begin{tabular}{|c|c|c|c|c|c|c|c|c|c|c|c|c|c|c|}
\hline \multirow{2}{*}{$\begin{array}{l}\text { heavy- } \\
\text { atom } \\
\text { compd }\end{array}$} & \multirow{2}{*}{$\begin{array}{l}\text { soaking } \\
\text { concn } \\
(\mathrm{mM})\end{array}$} & \multirow{2}{*}{$\begin{array}{l}\text { time } \\
\text { (days) }\end{array}$} & \multirow{2}{*}{$\begin{array}{c}\text { resolu- } \\
\text { tion } \\
(\AA)\end{array}$} & \multirow{2}{*}{$\begin{array}{l}R_{F}^{\text {int a }} \\
(\%)\end{array}$} & \multirow{2}{*}{$\begin{array}{l}R_{F}^{\text {nat a }} \\
(\%)\end{array}$} & \multicolumn{3}{|c|}{ fractional coordinates } & \multirow{2}{*}{$\begin{array}{l}\text { occu- } \\
\text { pancy } \\
(\%)\end{array}$} & \multirow{2}{*}{$\begin{array}{l}\text { temp } \\
\text { factor } \\
\left(\AA^{2}\right)\end{array}$} & \multicolumn{4}{|c|}{ phasing power $F / E^{b}$ in ranges $(\AA)$} \\
\hline & & & & & & $x$ & $y$ & $z$ & & & $\infty-5.9$ & $5.9-4.5$ & $4.5-3.4$ & $3.4-3.0$ \\
\hline PHMB $^{c}$ & 1.0 & 7 & 3.0 & 12.3 & 17.5 & $\begin{array}{l}0.778 \\
0.929 \\
0.632 \\
0.314\end{array}$ & $\begin{array}{l}0.477 \\
0.925 \\
0.644 \\
0.634\end{array}$ & $\begin{array}{l}0.004 \\
0.223 \\
0.013 \\
0.161\end{array}$ & $\begin{array}{r}100 \\
27 \\
20 \\
20\end{array}$ & $\begin{array}{l}20 \\
42 \\
20 \\
41\end{array}$ & 1.4 & 1.3 & 1.0 & 0.8 \\
\hline $\mathrm{HMSA}^{c}$ & 2.0 & 1 & 3.0 & 10.4 & 15.0 & $\begin{array}{l}0.134 \\
0.603 \\
0.308 \\
0.502 \\
0.781\end{array}$ & $\begin{array}{l}0.837 \\
0.644 \\
0.658 \\
0.179 \\
0.469\end{array}$ & $\begin{array}{l}0.011 \\
0.014 \\
0.161 \\
0.062 \\
0.004\end{array}$ & $\begin{array}{l}59 \\
53 \\
36 \\
31 \\
26\end{array}$ & $\begin{array}{l}25 \\
23 \\
42 \\
35 \\
31\end{array}$ & 0.9 & 1.0 & 0.9 & 0.8 \\
\hline $\mathrm{K}_{3} \mathrm{UO}_{2} \mathrm{~F}_{5}$ & 1.0 & 15 & 3.4 & 8.1 & 13.8 & $\begin{array}{l}0.978 \\
0.813 \\
0.986 \\
0.758 \\
0.047\end{array}$ & $\begin{array}{l}0.008 \\
0.464 \\
0.961 \\
0.459 \\
0.848\end{array}$ & $\begin{array}{l}0.095 \\
0.152 \\
0.115 \\
0.108 \\
0.118\end{array}$ & $\begin{array}{l}80 \\
56 \\
73 \\
39 \\
34\end{array}$ & $\begin{array}{r}40 \\
52 \\
117 \\
72 \\
28\end{array}$ & 1.3 & 1.2 & 0.7 & \\
\hline
\end{tabular}

${ }^{\circ}$ The $R_{F}$ factor between two data sets 1 and 2 is defined as $R_{F}=2 \sum\left|F_{1}-F_{2}\right| / \sum\left(F_{1}+F_{2}\right)$, where $F$ denotes structure factor amplitudes. For $R_{F}^{\text {int }}$ the data sets are the symmetry-related reflections zones $h k 1$ and $h k \bar{I} ; R_{F}^{\text {nat }}$ compares the derivative data set with the native set. ${ }^{b}$ The phasing power is the ratio between rms heavy-atom structure factor $F$ and rms lack of closure error $E$. ' PHMB, $p$-(hydroxymercurio)benzoate; HMSA, 3- or 5-(hydroxymercurio)salicylic acid.

shell. By using seven different crystals, all of the $\sim 18000$ independent reflections were measured twice and merged. Due to low intensities, the quality of the data decreased appreciably beyond 3.0- $\AA$ resolution. While the internal $R_{F}$ factor (for definition see Table I) of the merged data set was $5.8 \%$ for the resolution range $\infty-3.0 \AA$ ( 11000 reflections), it was as high as $30.3 \%$ in the range $3.0-2.5 \AA$. Also, the average radiation damage endured by a reflection was quite different: about $10 \%$ in the range $\infty-3.0 \AA$ and about $18 \%$ in the range $3.0-2.5 \AA$.

In addition to the diffractometer measurements, we collected another native data set to $1.85-\AA$ resolution on film (Reflex 25, CEA, Sweden), using the X11 synchrotron source at DESY, Hamburg. The films were digitized on densitometers (Optronics) at DESY and at the Biozentrum Basel. The data were reduced with the program suite MOSCo, resulting in structure factor amplitudes for $92 \%$ of all independent reflections out to $1.85-\AA$ resolution. The merging $R$-factor on intensities, which equals $\sum_{h k l} \sum_{i l}\left|I_{i}-I_{h k l}\right| / \sum_{h k l} \sum_{i} I_{i}$ where $I_{h k l}$ is the average of reflection $h k l$, was $14.9 \%$. Film and diffractometer data were combined in the range $\infty-3.0 \AA$; the $R_{F}$-factor between the data sets was $11.1 \%$. In the range 3.0-2.5 $\AA$, we dispensed with the diffractometer data because the film data were better. Since the film data were collected rather late in the analysis, the combined data set, which contained $95 \%$ of all independent reflections to 1.85 - $\AA$ resolution, was only used at the last stage of the refinement, i.e., the simulated annealing procedure.

Mir Phases. For mir analysis we soaked the crystals with 21 different heavy-atom compounds under various conditions. Intensity changes were monitored by precession photographs of the $0 \mathrm{kl}$ plane (camera Y925, rotating anode generator GX6, Enraf-Nonius, The Netherlands). Crystals soaked with 11 different heavy-atom compounds were measured on the diffractometer. Three among these were used for phase determination (Table I). As the initial step, the difference Patterson of the PHMB derivative was interpreted in terms of the main site. All other heavy-atom positions were found by difference Fourier syntheses. They were refined and phases were determined with the method of Dickerson et al. (1968). The mean figure of merit was $55 \%$ in accordance with the rather low phasing power, which dropped to the 1.0 limit around $4-\AA \AA$ resolution (Table I). The heavy-atom parameters are given in Table I. They were used to calculate mir phases and a corresponding electron density map.
By use of this map, the positions of the two adenylate kinase molecules could be established in the asymmetric unit by fitting the known structure of AK1pig (Dreusicke et al., 1988), with its nine $\alpha$-helices common to all adenylate kinases, to the visible $\alpha$-helices of the map. All model manipulations were done on an interactive display system (Model PS-330, Evans \& Sutherland) using the program FRODO (Jones, 1978; Pflugrath et al., 1984). Continuous chain tracing, however, was not possible. Since AK3 is a large variant in contrast to the homologous small variant AK1 pig (Schulz et al., 1986) an additional insert domain of about 30 residues, which contains no $\alpha$-helix, is expected to start around residue 125 of AK3 (Egner et al., 1987). The mir map, however, had no appropriate density for this domain.

Refinement Attempt Based on NCS. Although the mir map yielded only the rough positions of the two molecules, it was hoped that noncrystallographic symmetry (NCS) would allow us to establish the molecular structure in detail. First, we replaced the fitted AKl pig (a small variant) by AKyst, because AKyst is a large variant adenylate kinase like AK3. Then, all residues were replaced by alanines and the reciprocal-space rigid-body refinement program TRAREF (Huber \& Schneider, 1985 ) was run to refine the positions of the two independent molecules. This procedure yielded the NCS parameters given in Table II (entry AKystA) at an $R_{F}$ factor of $53.3 \%$.

The result was used as starting point for a real-space refinement with a program called NCSREF that minimized the density deviations $\sum_{i}\left(\rho_{1, i}-\rho_{2, i}\right)^{2}$ of related grid points $i$ within the mir map. Here, the envelopes of molecules 1 and 2 were defined as appropriately sized spheres around the respective centers of mass, and quadratic interpolation was applied to compute the density at noninteger grid points. The result is given in Table II (entry [AKyM]). In retrospect, the realspace NCS parameters were better than those derived from reciprocal space, as they were closer to the more accurate data at a later stage of the analysis (i.e., entry MAIN of Table II; see $R 2$ and $T y$ ). Using the real-space NCS parameters, we produced an averaged mir density map, which still did not show the insert domain and still did not allow continuous chain tracing.

The poly(alanine) model AKystA, which is based on the structure of AKyst, was then processed in a constrained-restrained refinement using the program coRels (Sussman et al., 1977) in the resolution range 15-6 $\AA$. For this purpose, CORELS was modified to allow the input of NCS constraints 


\begin{tabular}{|c|c|c|c|c|c|c|c|c|c|c|c|c|}
\hline \multirow[b]{2}{*}{$\operatorname{program}^{a}$} & \multirow{2}{*}{$\begin{array}{l}\text { resolution } \\
\text { range }(\AA)\end{array}$} & \multirow[b]{2}{*}{ model $^{b}$} & \multirow[b]{2}{*}{$\operatorname{map}^{c}$} & \multicolumn{3}{|c|}{$\begin{array}{l}\text { center of mass of } \\
\text { reference model } \\
\text { (fractional) }\end{array}$} & \multicolumn{3}{|c|}{ rotations $^{d}(\mathrm{deg})$} & \multicolumn{3}{|c|}{ translations (fractional) } \\
\hline & & & & $x$ & $y$ & $z$ & $\overline{R 1}$ & $R 2$ & $R 3$ & $T x$ & $T y$ & $T z$ \\
\hline TRAREF & $15-6$ & AKystA & & 0.10 & 0.54 & 0.38 & 0 & 3 & 8 & 0.58 & 0.07 & -0.26 \\
\hline NCSREF & $\infty-6$ & [AKyM] & $\operatorname{mir}$ & 0.08 & 0.55 & 0.38 & 2 & 10 & 10 & 0.59 & 0.15 & -0.29 \\
\hline NCSREF & $\infty-3$ & [AK3M] & solv fl & 0.08 & 0.55 & 0.38 & 0 & 12 & 10 & 0.58 & 0.19 & -0.29 \\
\hline NCSREF & $\infty-3$ & [INSD] & solv fl & -0.34 & 0.25 & 0.42 & -10 & 9 & 9 & 0.54 & 0.13 & -0.29 \\
\hline XPLOR & $10-1.9$ & MAIN & & 0.11 & 0.62 & 0.36 & 0 & 10 & 10 & 0.56 & 0.16 & -0.29 \\
\hline XPLOR & $10-1.9$ & INSERT & & -0.35 & 0.31 & 0.41 & -9 & 7 & 8 & 0.55 & 0.10 & -0.27 \\
\hline XPLOR & $10-1.9$ & AMPbd & & 0.19 & 0.50 & 0.46 & 3 & 8 & 15 & 0.50 & 0.10 & -0.27 \\
\hline
\end{tabular}

${ }^{\circ}$ The reciprocal-space refinement program TRAREF uses the model. In the real-space refinement program NCSREF, the model determines only the compared density region, which is an appropriately sized sphere around the center of mass for the entries [AKyM] and [AK3M] and a domain envelope with a distance of $3 \AA$ from the surface atoms for the entry [INSD]. The program XPLOR derives the NCS parameters from the model. ${ }^{b}$ The brackets indicate that the model is only used for defining the density region. Models were as follows: AKystA, poly(Ala) built into the structure of yeast adenylate kinase; [AKyM], AKystA without insert; [AK3M], the model of AK3 without the insert adjusted to the solvent-flattened map before starting the simulated annealing refinement with XPLOR; [INSD], the insert domain as initially fitted to the solvent-flattened map; MAIN, residues 5-32, 69-123 and 163-218 of the present AK3 model after the refinement with XPLOR; AMPbd, residues 33-68 of the present AK3

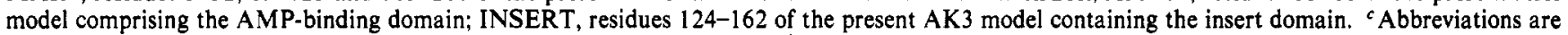
mir, map calculated from mir phases; solv $\mathrm{fl}$, solvent-flattened mir map. ${ }^{d}$ Eulerian-type angles are used, where $R 1$ denotes a rotation around $z, R 2$ a rotation around $x^{\prime}$, and $R 3$ a rotation around $y^{\prime \prime}$.
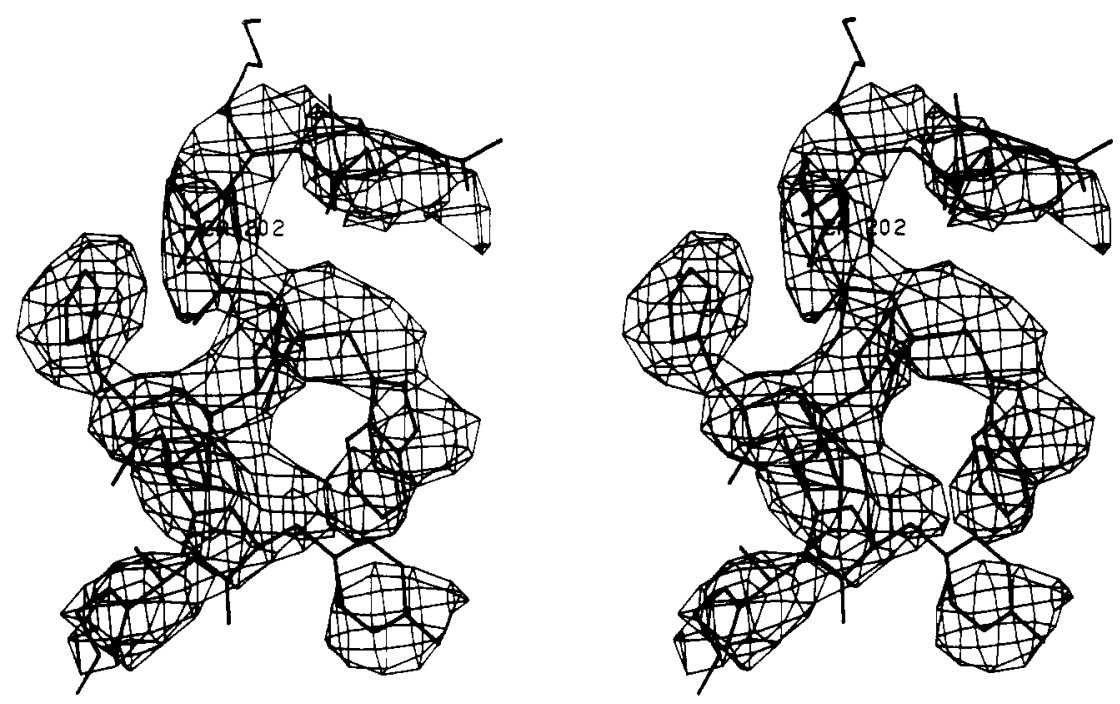

FIGURE 1: Stereoview of the nonaveraged solvent-flattened mir electron density map at $3.0-\AA$ resolution with the present refined model of the polypeptide segment -Asn-Lys-Ile-Trp-Pro-His-Val-Tyr-Ala- of molecule 1. The backbone is extended beyond both ends. The contour level is $15 \%$ of the maximum density. For clarity, density not directly associated with the model has been deleted.

and of mir phases of reflections with the respective figures of merit. The NCS was fixed to the real-space parameters, and 10 rigid groups were defined corresponding to the central $\beta$-pleated sheet and the nine helices; the insert domain was omitted. Subsequently, the resolution range was enlarged, the known sequence of AK3 (Tomasselli et al., 1986) was built into the model, and the sizes of the rigid groups were gradually reduced to single amino acid residues. Also, the mir phases weighted with their figures of merit were introduced. The refinement converged at $R_{F}=42.3 \%$ in the resolution range 10-3 $\AA$ with a medium-quality model geometry (rms bond length deviation $0.14 \AA$ ).

Restrained refinement was continued with the program PROFFT (Hendrickson \& Konnert, 1980; Finzel, 1987), which was run for 15 cycles in the resolution range 10-3 $\AA$ as well as for 10 cycles in the range 5-2.5 $\AA$ (15511 reflections, diffractometer data). Several model adjustments were done by using $2 F_{o}-F_{\mathrm{c}}$ maps and omit maps (Bhat \& Cohen, 1984). The procedure converged at $R_{F}=36.4 \%$ with reasonable model geometry; the rms deviations of bond lengths and bond angles were $0.063 \AA$ and $8.0^{\circ}$, respectively. The $F_{\mathrm{o}}-F_{\mathrm{c}}$ difference map showed the bound substrate AMP as the most prominent density in both molecules, but it contained no ap- propriate density for the insert domain.

Solvent Flattening and Simulated Annealing. In view of the missing insert domain, we restarted data processing by applying solvent flattening and phase combination (Wang, 1985 ) to the mir phases at $3-\AA$ resolution (Table I). The crystal solvent content was taken as $45 \%$, which amounts to $86 \%$ of the solvent content calculated from the unit cell parameters (52\%, see above). Molecular masks were defined by local density averaging over a sphere of $10-\AA$ radius by using the algorithm of Leslie (1987). Altogether, we calculated 3 masks and ran through 15 iterations. The mean figure of merit increased from 55 to $85 \%$. The solvent-flattened map was appreciably better than the mir map; its quality is exemplified in Figure 1. The NCS parameters were redetermined from this map by using the real-space refinement NCSREF (data not given in Table II); they deviated only slightly from those derived from the mir map (entry [AKyM] of Table II). An NCS-averaged solvent-flattened mir map at $3-\AA$ resolution was produced as the final model-independent map.

To this map we fitted the final model of the PROFFT refinement. It consisted of the AK3 sequence without the insert domain. The fit showed that (i) the density is still not good enough to allow continuous chain tracing without underlying 
Table III: Simulated Annealing Refinement with XPLOR

\begin{tabular}{|c|c|c|c|c|c|c|}
\hline \multirow[b]{2}{*}{ round $^{a}$} & \multirow[b]{2}{*}{ resolution range ( $\AA$ ) } & \multicolumn{5}{|c|}{$R_{F}$-factors $(\%)$} \\
\hline & & $\overline{\min -1^{b}}$ & md $-2000^{c}$ & $\mathrm{md}-300^{d}$ & $\min -2^{e}$ & $\min -B$ \\
\hline 1 & $8-3$ & 41.0 & 36.1 & 31.9 & 30.4 & $g$ \\
\hline 2 & $6-2$ & $g$ & 41.0 & 37.5 & 36.6 & 33.8 \\
\hline 3 & $6-2$ & 35.9 & 37.2 & 33.5 & 32.4 & 31.5 \\
\hline 4 & $10-2$ & 33.6 & 37.5 & 33.2 & 32.0 & 31.5 \\
\hline 5 & $10-1.9$ & 33.7 & 37.5 & 33.5 & 32.5 & 32.0 \\
\hline 6 & $10-1.9$ & 30.6 & $g$ & 30.6 & 28.9 & 28.4 \\
\hline
\end{tabular}

${ }^{a}$ The CPU time for one round was 14 days on a MicroVax-II. The model was rebuilt after each round, except for round 1 . The weights for the $X$-ray structure factor amplitude (WA) and phase restraints (WP) were chosen such that the gradient of the X-ray energy was comparable in magnitude to the gradient of the empirical potential energy of a molecular dynamics simulation in which WA and WP were set to zero (Bruenger et al., 1987). ${ }^{b}$ First energy minimization. 'Molecular dynamics at $2000 \mathrm{~K}$ run for $0.5 \mathrm{ps}$. ${ }^{d}$ Molecular dynamics at $300 \mathrm{~K}$ run for $0.25 \mathrm{ps}$. 3 Second energy minimization. ${ }^{f}$ Temperature factor refinement. ${ }^{8}$ This step was omitted.

homologous structure, (ii) the bound substrate AMP had well-developed density, and (iii) there exists now density for the insert domain. Furthermore, it became clear that the CORELS/PROFFT refinement had converged to a partially incorrect model, as several $\alpha$-helices were longitudinally shifted by about one helix turn. The model was adjusted to the map and supplemented by adding AMP.

Since the respective density did not allow chain tracing, the model of the insert domain was initially taken from AKyst$A p_{5} A$ by rotating this domain around the two connecting residues and by introducing the sequence of AK3. The densities of the two insert domains were then subjected to NCSREF, yielding the NCS parameters given in Table II (entry [INSD]) with a density correlation coefficient +0.55 , which is in the same range as the coefficient for the main part of the molecule (Table II, entry [AK3M]). The NCS parameters of the insert domains deviate significantly from those of the main parts, indicating different relative positions. This difference was later confirmed in the refined model (see Table II, entry INSERT). The fitting procedure yielded a still rough but now complete and in general correct model, which was then duplicated by using the current NCS parameters and subjected to simulated annealing.

For simulated annealing, we used the program XPLOR (Bruenger et al., 1987). The present model was subdivided into the main part (residues 5-32, 69-123, and 163-218), the insert domain (residues 124-162), and the AMP-binding part (residues 33-68). The NCS parameters of these domains were refined separately. The procedure was started in the resolution range 8-3 $\AA$. The resolution was gradually increased following the protocol given in Table III. By use of NCS-averaged and regular $2 F_{\mathrm{o}}-F_{\mathrm{c}}$ maps as well as regular $F_{\mathrm{o}}-F_{\mathrm{c}}$ maps, the model was rebuilt after each round except for the first one. During the refinement, the chain fold of the insert domain had to be changed appreciably. Round 6 resulted in $R_{F}=28.4 \%$ in the resolution range $10-1.9 \AA$ at good model geometry; the rms deviations of bond lengths and bond angles were 0.017 $\AA$ and $3.6^{\circ}$, respectively. At this point the $F_{0}-F_{\mathrm{c}}$ map contained merely minor peaks, indicating missing solvent molecules or smallish shifts of side- and main-chain atoms. Therefore, we consider the resulting model and in particular the chain path of the insert domain (Figures 2 and 3 ) as essentially correct. The model lacks 11 residues at the chain ends, residues 1-4 and 219-225, because they have no appropriate density. It is quite possible that these residues are highly mobile and thus evade detection.

\section{RESUlts AND Discussion}

The present analysis yielded the structures of two crystallographically independent AK3-AMP complexes. The chain folds and the substrate positions of both complexes are virtually identical. Both chain tracings are unambiguous as judged from the present $2 F_{0}-F_{\mathrm{c}}$ map, from the present $F_{0}-F_{\mathrm{c}}$ map, and from the present $R_{F}$-factor of $28.4 \%$ at $1.9-\AA$ resolution without solvent molecules at excellent geometry. The four $\mathrm{N}$-terminal and the seven C-terminal residues of both chains, however, have not yet been fitted to the density; possibly they have no defined conformation. The chain fold of the insert domain is now clear. All $B$-factors are well behaved; the $B$-factors of the insert domain are on average the same as in the rest of the molecule. The observed chain fold differs somewhat from the published chain folds of the homologous enzymes from yeast (Egner et al., 1987) and Escherichia coli (Mueller \& Schulz, 1988) that were based on rather weak densities. The chain paths in the insert domains of the yeast and $E$. coli enzymes are presently reexamined.

Domain Flexibility and Induced Fit Movements. A subdivision of the enzyme into the three domains MAIN ( $\mathrm{N}-32$, 69-123, and 163-C), AMPbd (33-68), and INSERT (124-162) and separate determinations of the NCS parameters revealed domain flexibility. As shown in Table II, the NCS parameters for INSERT and AMPbd differ slightly but significantly from MAIN and from each other. The enzyme seems to be composed of three rigid bodies, the arrangement of which depends on crystal packing, indicating relative mobility. Such domain rearrangements are well-known from other proteins, which contain domains serially ordered along the polypeptide chain and thus connected by single strands (Schulz, 1981), as for instance immunoglobulins (Huber, 1976). Less frequently, molecular regions connected by two (as in AK3) or more strands can be assigned as domains because they undergo large movements as rigid bodies. Such a domain has been observed for instance with hexokinase (Shoham \& Steitz, 1982).

The enzyme AK 3 belongs to the group of large variants within the adenylate kinase family. AK3 shows a reasonable level of homology to other adenylate kinases (Schulz et al., 1986) so that identical chain folds can be expected. The chain fold of AK3-AMP together with the chain fold of AK1 pig is given in Figure 2. AKl pig is a small variant and had been crystallized without substrate (Dreusicke et al., 1988); its conformation has been confirmed by an X-ray analysis of the small variant AK1 carp (Reuner et al., 1988). The overlay in Figure 2 shows good agreement in domain MAIN. A large change occurred, however, with respect to domain AMPbd. The bound substrate AMP seems to have caused a movement of this domain over a distance of up to $10 \AA$, closing the deep cleft. Domain INSERT is missing in AK1 pig.

A structural comparison with the large variant adenylate kinase from $E$. coli as complexed to the double-substratemimicking inhibitor $A p_{5} A$ is given in Figure 3. Again, this figure shows good agreement in domain MAIN. Here, also 

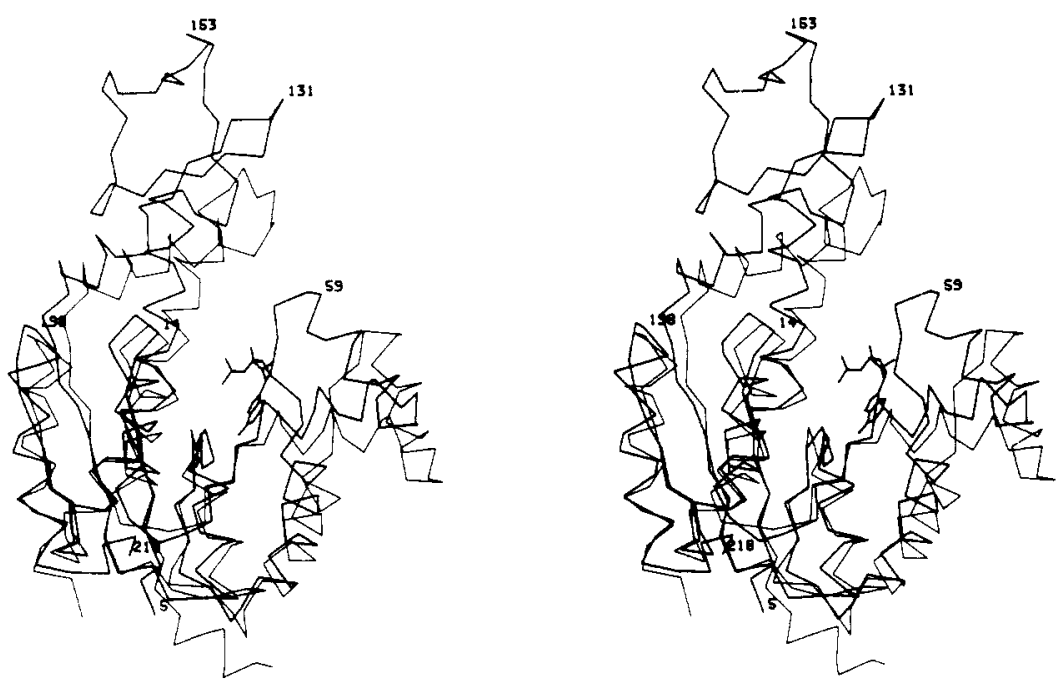

FIGURE 2: Stereo drawing of the $\mathrm{C}_{\alpha}$ backbone of the AK3-AMP complex molecule 1 (thick lines) overlaid to the backbone of AK1 pig (thin lines; Dreusicke et al., 1988). The overlay is based on the central $\beta$-pleated sheet. Some residue numbers of AK3 are given.
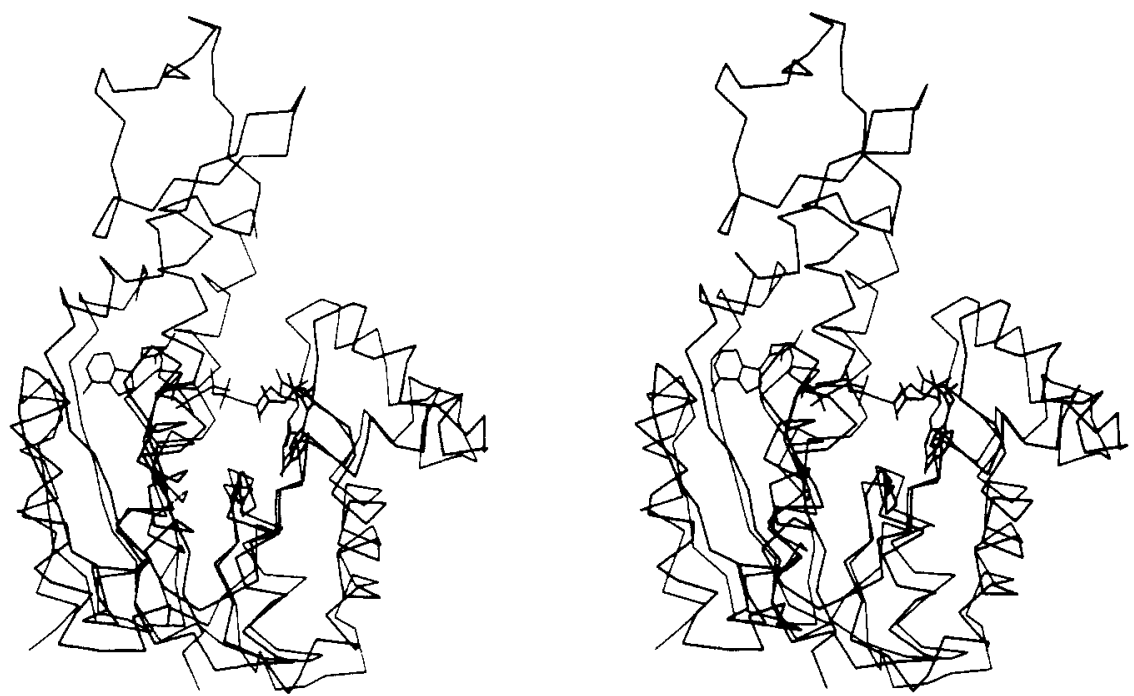

FIGURE 3: Overlay of the $C_{\alpha}$ backbone of the AK3-AMP complex molecule 1 (thick lines) with the backbone of AKeco together with the bound $\mathrm{Ap}_{5} \mathrm{~A}$ (thin lines; Mueller \& Schulz, 1988). The domain INSERT of AKeco has been omitted for clarity; also, its chain fold is not well based on density.

the AMPbd domains are rather well superimposed, although in $\mathrm{AKeco}-\mathrm{Ap}_{s} \mathrm{~A}, \mathrm{AMPbd}$ is slightly closer to MAIN than in AK3-AMP. This indicates that domain AMPbd closes the cleft at the active center even better if also the second substrate, $\mathrm{ATP}$, is bound. The underlying assumption that $\mathrm{Ap}_{5} \mathrm{~A}$ mimics both substrates, ATP and AMP, is discussed below.

For clarity, the domain INSERT of $A K e c o-A p_{5} A$ has been omitted from Figure 3. Its spatial location in $A K e c o-A p_{5} A$ is essentially the same as in AKyst- $A p_{5} \mathrm{~A}$. Both locations are clearly established, although the chain paths within the domains have to be reexamined. In both structures, domain INSERT covers the phosphates of $\mathrm{Ap}_{5} \mathrm{~A}$ so that the complex has a rather globular shape with a buried catalytic center. This is in gross contrast to the structures of the two crystallographically independent molecules of AK3, where domain INSERT is far away from the phosphates. One may therefore conclude that, on binding of the second substrate, GTP for AK 3 or ATP for the other adenylate kinases, there occurs a very large domain movement to cover up the catalytic center and to protect it against water.

Substrate-Binding Sites. The crystalline complex AKyst$A p_{5} A$ (Egner et al., 1987) showed clearly the locations of both adenines. Because of the covalent symmetry of $\mathrm{Ap}_{5} \mathrm{~A}$, how- ever, the ATP site could not be distinguished from the AMP site. Judging from the binding strengths as represented by the observed contact intimacies, adenine-B of $A p_{5} A$ had been assigned to the more specific AMP site and adenine-A to the less specific ATP site. This analysis was confirmed in all aspects by the structure elucidation of the homologous complex

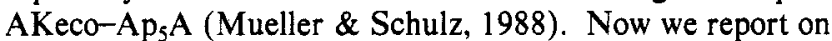
another homologous structure, where only one of the substrates is bound. Figure 3 shows that AMP of AK3-AMP binds in a manner virtually identical with adenine- $B$ of $A p_{5} A$ in $A K e c o-A p_{5} A$. We therefore conclude that adenine-B belongs to the AMP site of the adenylate kinases, which points to adenine- $A$ belonging to the ATP site.

In the initially elucidated complex structure $\mathbf{A K y s t}-\mathrm{Ap}_{5} \mathbf{A}$, this correspondence was called in question because the contacts of adenine-A with the enzyme were rather weak and the contacted polypeptide segments at this site were much less conserved during evolution than others [see Table 3 of Egner et al. (1987)]. Doubt turned to wondering when the second complex structure $\mathrm{AKeco}-\mathrm{Ap}_{5} \mathrm{~A}$ came out as virtually identical. Now, we know the structure of the GTP-binding Ha-ras p21 protein (deVos et al., 1988), which shows sequence homology with the adenylate kinases at the giant anion hole 
Table IV: Atoms Contacting the Substrate AMP in the Present Model

\begin{tabular}{|c|c|c|c|c|}
\hline $\begin{array}{l}\text { part of } \\
\text { substrate }\end{array}$ & residue ${ }^{a}$ & $\begin{array}{l}\text { homology } \\
\text { region }^{b}\end{array}$ & $\begin{array}{l}\text { contacting } \\
\text { atoms }^{a} \\
\text { (residue) }\end{array}$ & $\begin{array}{c}\text { close } \\
\text { distances }^{c} \\
\text { (residue... } \\
\text { AMP) }\end{array}$ \\
\hline \multirow[t]{9}{*}{ adenine } & $\operatorname{Ser} 36^{d}$ & B & $\mathrm{OG}, \mathrm{CB}$ & OG...N7 \\
\hline & Leu40 & $\mathrm{B}^{*}$ & CD1 & \\
\hline & Leu63 & $\mathrm{C}^{*}$ & $\mathrm{CD} 2, \mathrm{CA}, \mathrm{CB}$ & \\
\hline & Ile64 & $\mathrm{C}$ & $\mathrm{N}, \mathrm{O}, \mathrm{CB}$ & No..N3 \\
\hline & Met69 & C & CG, SD & \\
\hline & Gly89 & $D^{*}$ & $\mathrm{O}, \mathrm{C}$ & O...N10 \\
\hline & Phe90 & D & $\mathrm{CD} 2, \mathrm{CA}$ & \\
\hline & Arg92 & $D^{*}$ & $\mathrm{CB}, \mathrm{NH} 2, \mathrm{~N}$ & $\mathrm{CB} \cdots \mathrm{N} 10$ \\
\hline & $G \ln 96$ & $\mathrm{D}^{*}$ & $\mathrm{NE} 2, \mathrm{OE} 1, \mathrm{CD}$ & NE2 $\cdots N 1$ \\
\hline \multirow[t]{6}{*}{ ribose } & Gly37 & $\mathrm{B}^{*}$ & $\mathrm{CA}$ & \\
\hline & Leu40 & $\mathrm{B}^{*}$ & CD1 & \\
\hline & Ile58 & C & $\mathrm{CG} 1, \mathrm{CD} 1$ & \\
\hline & Lys62 & $\mathrm{C}$ & $\mathrm{O}, \mathrm{C}$ & $\mathrm{O} \cdots \mathrm{O} 2 \mathrm{R}$ \\
\hline & Leu63 & $C^{*}$ & $\mathrm{CA}$ & \\
\hline & Arg92 & $D^{*}$ & NH1 & \\
\hline \multirow[t]{3}{*}{ phosphate } & Gly37 & $\mathrm{B}^{*}$ & $\mathrm{CA}$ & \\
\hline & Arg41 & $\mathrm{B}^{*}$ & NH1 & NH1 $\ldots$ OP \\
\hline & Arg92 & $D^{*}$ & NH1 & \\
\hline
\end{tabular}

an atom and the corresponding residue are listed if its distance to any AMP atom is below $4 \AA$ (average over molecules 1 and 2). ${ }^{b}$ The homology region is defined as by Schulz et al. (1986). Asterisks denote residues conserved in all adenylate kinases. ${ }^{~}$ These are atom distances below $3.5 \AA$ (average over molecules 1 and 2 ). ${ }^{d}$ Although not conserved, this Ser is only exchanged for Thr, which also has an OG hy. droxyl (Schulz et al., 1986).

(Dreusicke \& Schulz, 1986) and, in the corrected form (Pai et al., 1989), chain-fold homology in the domain MAIN, and we realize that site adenine-A corresponds to the location of GTP. Thus, we conclude that adenine-A belongs to the ATP site and that the sequence around the base of the bound nucleotide is not well conserved because adenylate kinases bind the base less avidly than the ribose triphosphate moiety. This assignment confirms that bound $\mathrm{Ap}_{5} \mathrm{~A}$ is mimicking the bound substrates ATP and AMP.

Several proposals for the nucleotide-binding sites of adenylate kinases had been put forward. Previous crystal soaking experiments with $\mathrm{AK} 1 \mathrm{pig}$ had shown a site corresponding to adenine-B of $\mathrm{Ap}_{5} \mathrm{~A}$ in crystal form $\mathrm{A}$ and another site in crystal form B (Pai et al., 1977). The authors suggested that the adenine-B site binds ATP because only in this way could the transferred phosphoryl group be located close to the prominent sulfate bound in the giant anion hole; the possibility of a large movement of domain AMPbd as seen in Figure 2 was not expected at all. The second site, which was found in crystal form B of AK1pig, was probably an artifact caused by the mir phases being biased toward the main heavy-atom position in conjunction with a partial crystal transition from form B to form A (Klein, 1988). In the following, ATP and AMP sites were also derived from nuclear magnetic resonance measurements (Smith \& Mildvan, 1982; Fry et al., 1985, 1986, 1987, 1988; Shyy et al., 1987; Roesch et al., 1989), but for none of them do we find correspondence with our results. The reason for the discrepancies is not obvious to us.

In our solvent-flattened NCS-averaged map, which is the final model-independent map, there is no indication of any additional bound AMP. The same applies for the $F_{0}-F_{\mathrm{c}}$ map at the current (or any previous) state of the refinement. On the other hand, the density for AMP is well developed and is at equivalent positions in both molecules. The residual rms difference of the AMP atoms in both molecules is $0.3 \AA$, which is lower than the values of 0.4 and $1.3 \AA$ observed for the mainand side-chain atoms, respectively. More details of the AMP-binding site of AK3 are given in Table IV. A com- parison of the contacts between AMP and polypeptide in both independent molecules shows correspondence within about 0.5 $\AA$. In the refined structure, the average $B$-factor of the AMP molecules is $27 \AA^{2}$ as compared to $24 \AA^{2}$ for the polypeptide. There exists a temperature factor gradient with lower $B$-values at the adenine and higher ones at the phosphate, indicating that the adenine end of AMP is more tightly bound than the phosphate end. This binding strength difference may be related to the missing second substrate, which causes a movement of about $2 \AA$ of AMP together with domain AMPbd toward domain MAIN, tightening up the phosphate as derived from the comparison with $\mathrm{AKeco}-\mathrm{Ap}_{5} \mathrm{~A}$ in Figure 3.

As indicated in Table IV, most of the contacting residues are strictly conserved during evolution. The contacts with Ser36, Ile64, Gly89, and Gln96 show good hydrogen-bond geometries. Especially the latter three contacts determine the specificity for adenine. The ribose forms only one good hydrogen bond with the carbonyl of Lys62. With the binding geometry at hand, site-directed mutagenesis with the aim of changing the specificity toward nucleotides with other purine bases becomes possible.

\section{AdDED IN PROOF}

After further refinement, the present model corresponds to an $R$-factor of $18.9 \%$ in the resolution range $10-1.85 \AA$. The rms deviations of bond lengths and angles are $0.016 \AA$ and $3.2^{\circ}$, respectively. There are 381 water molecules in the asymmetric unit.

\section{ACKNOWLEDGMENTS}

We thank Dr. A. G. Tomasselli and Dr. L. H. Noda for providing us with the enzyme and Sabine Burger for producing the enzyme crystals. We also thank Dr. P. Andrew Karplus for discussions and the staff of EMBL Hamburg and especially Dr. K. Wilson for help with measuring the synchrotron data set and use of the MOSCO film evaluation package.

\section{REFERENCES}

Bhat, T. N., \& Cohen, G. H. (1984) J. Appl. Crystallogr. 17, 244-248.

Bruenger, A. T., Kuriyan, J., \& Karplus, M. (1987) Science $235,458-460$.

deVos, A. M., Tong, L., Milburn, M. V., Matias, P. M., Jancarik, J., Noguchi, S., Nishimura, S., Miura, K., Ohtsuka, E., \& Kim, S.-H. (1988) Science 239, 888-893.

Dickerson, R. E, Weinzierl, J. E., \& Palmer, R. A. (1968) Acta Crystallogr., Sect. B 24, 997-1003.

Dreusicke, D., \& Schulz, G. E. (1986) FEBS Lett. 208, 301-304.

Dreusicke, D., Karplus, P. A., \& Schulz, G. E. (1988) J. Mol. Biol. 199, 359-371.

Egner, U., Tomasselli, A. G., \& Schulz, G. E. (1987) J. Mol. Biol. 195, 649-658.

Finzel, B. C. (1987) J. Appl. Crystallogr. 20, 53-55.

Fry, D. C., Kuby, S. A., \& Mildvan, A. S. (1985) Biochemistry 24, 4680-4694.

Fry, D. C., Kuby, S. A., \& Mildvan, A. S. (1986) Proc. Natl. Acad. Sci. U.S.A. 83, 907-911.

Fry, D. C., Kuby, S. A., \& Mildvan, A. S. (1987) Biochemistry 26, 1645-1655.

Fry, D. C., Byler, D. M., Susi, H., Brown, E. M., Kuby, S. A., \& Mildvan, A. S. (1988) Biochemistry 27, 3588-3598.

Hendrickson, W. A., \& Konnert, J. H. (1980) in Computing in Crystallography (Diamond, R., Ramaseshan, S., \& Venkatesan, K., Eds.) pp 13.01-13.25, Indian Academy of Sciences, Bangalore, India. 
Huber, R. (1976) Trends Biochem. Sci. 1, 174-178.

Huber, R., \& Schneider, M. (1985) J. Appl. Crystallogr. 18, 165-169.

Hurley, J. B., Simon, M. I., Teplow, D. B., Robishaw, J. D., \& Gilmann, A. G. (1984) Science 226, 860-862.

Jencks, W. P. (1975) Adv. Enzymol. Relat. Areas Mol. Biol. 43, 219-410.

Jones, T. A. (1978) J. Appl. Crystallogr. 11, 268-272.

Karn, J., Brenner, S., \& Barnett, L. (1983) Proc. Natl. Acad. Sci. U.S.A. 80, 4253-4257.

Klein, C. (1988) Diploma thesis, Universität Freiburg i.Br., West Germany.

Leistler, B. (1987) Diploma thesis, Universität Freiburg i.Br., West Germany.

Leslie, A. G. W. (1987) Acta Crystallogr., Sect. A 43, 134-136.

Matthews, B. W. (1968) J. Mol. Biol. 33, 491-495.

Mueller, C. W., \& Schulz, G. E. (1988) J. Mol. Biol. 202, 909-912.

Pai, E. F., Sachsenheimer, W., Schirmer, R. H., \& Schulz, G. E. (1977) J. Mol. Biol. 114, 37-45.

Pai, E. F., Schulz, G. E., Tomasselli, A. G., \& Noda, L. H. (1983) J. Mol. Biol. 164, 347-350.

Pai, E. F., Kabsch, W., Krengel, U., Holmes, K. C., John, J., \& Wittinghofer, A. (1989) Nature 341, 209-214.

Pflugrath, J. W., Saper, M. A., \& Quiocho, F. A. (1984) in Methods and Applications in Crystallographic Computing (Hall, S., \& Ashida, T., Eds.) pp 404-407, Oxford University Press, London.

Reuner, C., Hable, M., Wilmanns, M., Kiefer, E., Schiltz, E.,
\& Schulz, G. E. (1988) Protein Sequences Data Anal. 1, 335-343.

Roesch, P., Klaus, W., Auer, M., \& Goody, R. S. (1989) Biochemistry 28, 4318-4325.

Schulz, G. E. (1981) Angew. Chem., Int. Ed. Engl. 20, 143-151.

Schulz, G. E., Schiltz, E., Tomasselli, A. G., Frank, R., Brune, M., Wittinghofer, A., \& Schirmer, R. H. (1986) Eur. J. Biochem. 161, 127-132.

Shoham, M., \& Steitz, T. A. (1982) Biochim. Biophys. Acta $705,380-384$.

Shyy, Y.-J., Tian, G., \& Tsai, M.-D. (1987) Biochemistry 26, 6411-6415.

Smith, G. M., \& Mildvan, A. S. (1982) Biochemistry 21, 6119-6123.

Sussman, J. L., Holbrook, S. R., Church, G. M., \& Kim, S. H. (1977) Acta Crystallogr., Sect. A 33, 800-844.

Thieme, R., Pai, E. F., Schirmer, R. H., \& Schulz, G. E. (1981) J. Mol. Biol. 152, 763-782.

Tomasselli, A. G., \& Noda, L. H. (1979) Eur. J. Biochem. 93, 263-270.

Tomasselli, A. G., Schirmer, R. H., \& Noda, L. H. (1979) Eur. J. Biochem. 93, 257-262.

Tomasselli, A. G., Frank, R., \& Schiltz, E. (1986) FEBS Lett. 202, 303-308.

Walker, J. E., Saraste, M., Runswick, M. J., \& Gay, N. J. (1982) EMBO J. 1, 945-951.

Wang, B. C. (1985) Methods Enzymol. 115, 90-112.

Wieland, B., Tomasselli, A. G., Noda, L. H., Frank, R., \& Schulz, G. E. (1984) Eur. J. Biochem. 143, 331-339. 